\title{
Aristofolia Ayala-Landa, a valid genus of Asilinae (Diptera, Asilidae)
}

\author{
Rodrigo Vieira ${ }^{1} \&$ José Manuel Ayala Landa ${ }^{2}$
}

\begin{abstract}
${ }^{1}$ Instituto Nacional de Pesquisas da Amazônia - INPA, CBIO - Programa de Pós-Graduação em Entomologia, Campus II, 69060-000 Manaus-AM, Brazil. rodrigo08vieira@gmail.com

${ }^{2} 1872$ W. Lagoon rd. Pleasanton, California 94566, USA. jmal1942@gmail.com
\end{abstract}

\begin{abstract}
Aristofolia Ayala-Landa, a valid genus of Asilinae (Diptera, Asilidae). The robber fly genus Aristofolia AyalaLanda, 1978 is a monotypic taxon of Asilinae. The status of Aristofolia is revalidated, and addenda to the original description of the genus is provided. The habitus, wings, male and female terminalia are described and illustrated.

KEYWORDS. Brachycera; Insecta; Neotropical; taxonomy; Venezuela.
\end{abstract}

Asilinae Latreille, 1802 is the most diverse subfamily of Asilidae, including 177 extant genera, and is distributed in all biogeographic regions, except Antarctica. Even though 66 genera are recognized from the Neotropical re-gion, only 18 occur in Brazil (Geller-Grimm 2004; Papavero 2009; Vieira 2012a).

Aristofolia Ayala-Landa, 1978 is a monotypic genus and its distribution is restricted to Venezuela. Specimens of Aristofolia have been collected on the savannas of the central plains (Llanos) of Venezuela, in the state of Guárico, 170 $\mathrm{m}$, during the dry season. This genus is characterized by the stylus of antenna which bears a leaf-like projection (Figs. 2, 13, 14) (Ayala-Landa 1978). Ayala-Landa (1978) commented on Aristofolia similarities with Lecania Macquart, 1838 and provided diagnostic characters for the genera Eicherax Bigot, 1857 and Cerozodus Bigot, 1857.

Geller-Grimm (2004) allocated Aristofolia as incertae sedis within Asilidae, while Papavero (2009) synonymized Aristofolia with Lecania. In this paper, the status of Aristofolia is revalidated. Discussion about the position of the genus on Asilidae and addenda to the original description are provided.

\section{MATERIAL AND METHODS}

This study is based on the examination of specimens housed at Instituto Nacional de Pesquisas da Amazônia (INPA), Manaus, Amazonas state, Brazil and the personal collection of Jose Manuel Ayala Landa (JMAC), Pleasanton, CA, USA.

Morphological terminology follows Cumming \& Wood (2009). Vieira's (2012b) techniques were used to examine the terminalia. After study and illustration, the detached parts were placed in microvials with glycerin and pinned with their respective specimen. The label data is cited in full, with the original spellings, punctuations, and dates. Information presented within square brackets is complementary data not included on the labels. Data for the same specimen but from different labels are separated by slashes (/).

\section{TAXONOMY}

Aristofolia Ayala-Landa, 1978

Type-species, Aristofolia lapila Ayala-Landa, 1978 (orig. des.). Aristofolia; Geller-Grimm, 2004: 508, Incertae sedis [Apocleinae?]. Lecania; Papavero, 2009: 30 (catalogue).

Comments. Papavero (2009, p. 30) synonymized Aristofolia with Lecania. However, this author did not explain the reason for this taxonomic change. Aristofolia clearly differs from Lecania mainly by the stylus of antenna. In Aristofolia, the stylus possesses a leaf-like projection (Figs. 2, 15), while in Lecania the stylus is setae-like. Furthermore, Aristofolia lapila, the type-species of Aristofolia, has at least two apical scutellar macrosetae, the male possesses an aedeagus with three short prongs (Fig. 11) and females have three spermathecae, while the species of Lecania do not have apical scutellar macrosetae, the male aedeagus has only two elongated prongs and the females have only two spermathecae.

In Asilinae, only males of Cerozodus have also a dilation in the stylus, however this dilation is situated at the basal region ventrally and postpedicel laterally compressed with the apex broadly truncate (Artigas \& Papavero 1995; Vieira et al. 2013). In Aristofolia, the leaf-like projection is located in the mid-apical region and the postpedicel is oval (Figs. 2, 15). Furthermore, the male terminalia of Aristofolia is similar to those in the genera of the Efferia group.

\section{Aristofolia lapila Ayala-Landa, 1978}

(Figs. 1-16)

Aristofolia lapila Ayala-Landa, 1978: 45, figs 1-8.

Comments. The original description of $A$. lapila contemplates the most important morphological characters used in taxonomy of Asilinae, however it lacks a description of the structures of the terminalia. 

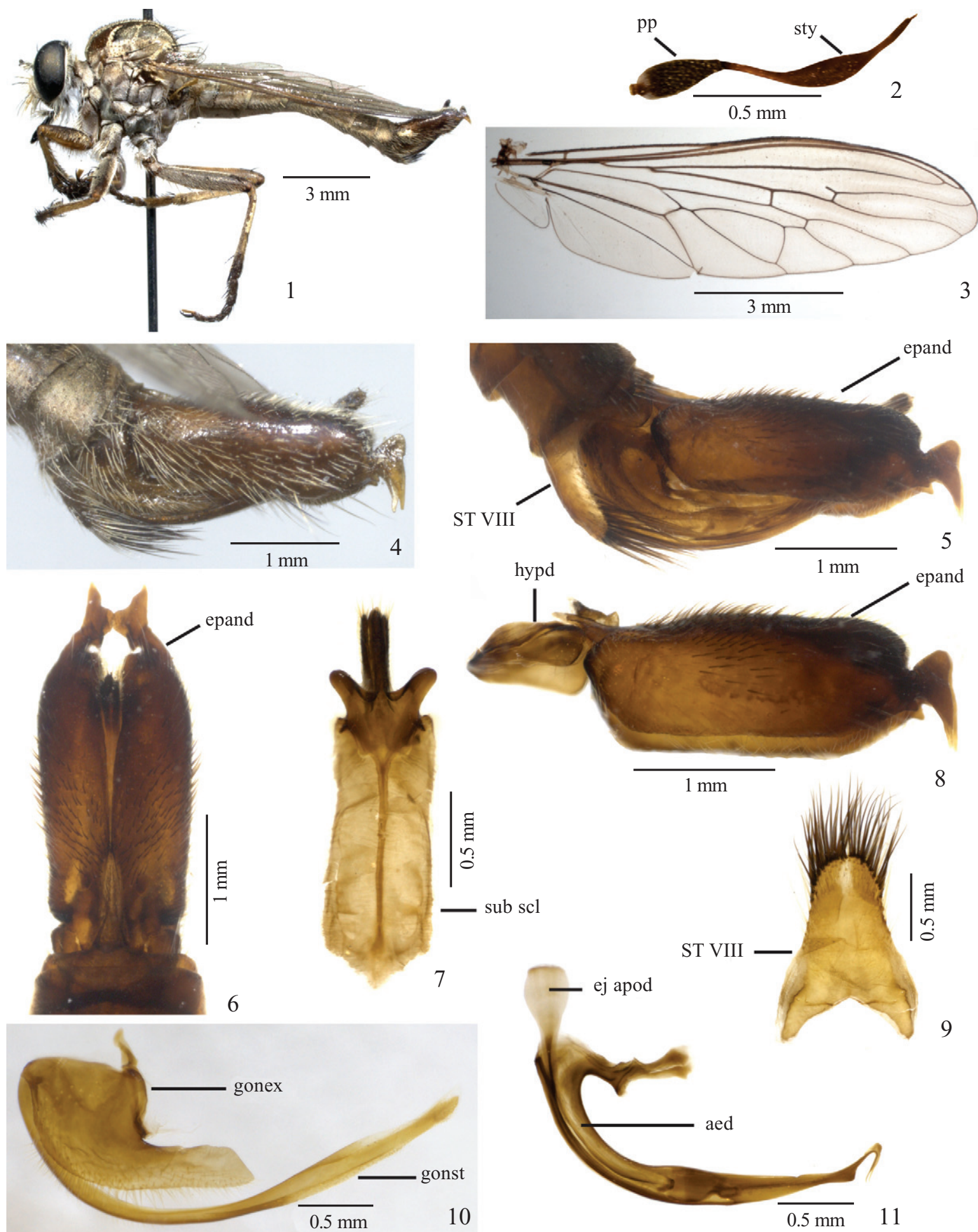

Figs. 1-11. Aristofolia lapila Ayala-Landa, 1978. Paratype male. 1. Habitus, lateral view; 2. Antennae; 3. Wing; 4. Male terminalia without treated in hot $10 \%$ $\mathrm{KOH}$, lateral view; 5. Male terminalia, lateral view; 6. Male terminalia, dorsal view; 7. Subepandrial sclerite; 8. Epandrium and hypandrium; 9. Sternite VIII; 10. Gonocoxite and gonostylus; 11. Aedeagus and ejaculatory apodeme, lateral view. Abbreviations: aed: aedeagus; ej apd: ejaculatory apodeme; epand: epandrium; goncx: gonocoxite; gonst: gonostylus; hypd: hypandrium; pp: postpedicel; ST VIII: sternite VIII; sty: stylus; sub scl: subepandrial sclerite.

Addenda to the original description. Head. Stylus with one element (Figs. 2, 15). Thorax. Prosternum separated from proepisternum. Prosternum triangular; no anatergal setae; Wing. Short stump vein supernumerary crossvein on $R_{4}$ not reaching base of $\mathrm{R}_{2+3}$ (Fig. 3); microtrichia on posterior wing margin arranged in a single plane. Abdomen. Male sternite VIII completely covering the hypandrium (Fig. 5); apical margin of male sternite VIII developed, rounded with long 

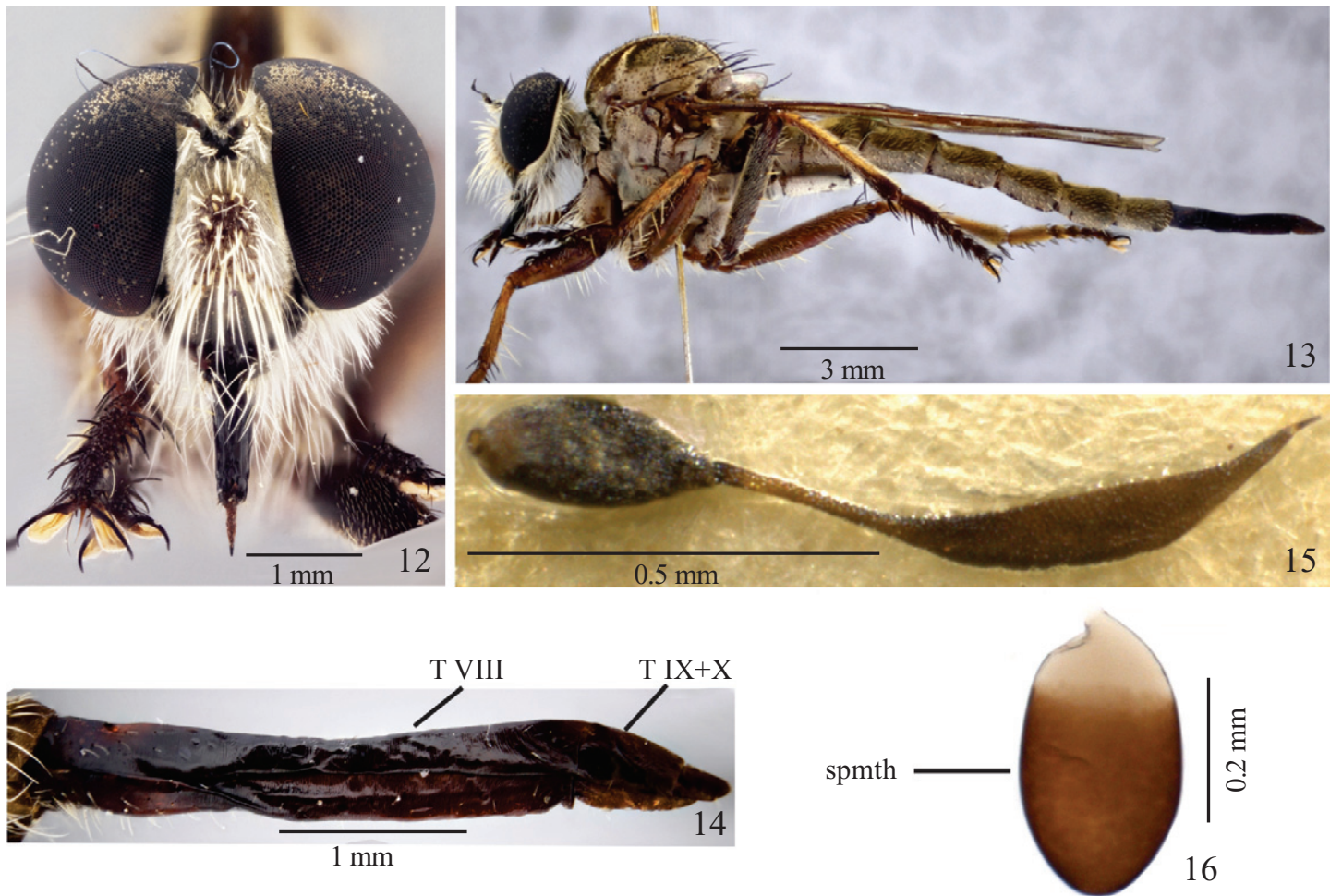

Figs. 12-16. Aristofolia lapila Ayala-Landa, 1978. Paratype female. 12. Head, frontal view; 13. Habitus, lateral view; 14. Ovipositor, lateral view; 15. Antenna, lateral view; 16. Capsule of spermathecae. Abbreviations: spmth: spermathecae; T VIII: tergite VIII; T IX + X: tergite IX + X.

setae (Fig. 9). Ventral margin with concavity V-shaped (Fig. 9). Male terminalia. Terminalia oblique to the axis of the body (Fig. 1); ventral margin of epandrium straight, in lateral view (Figs. 5, 8); hypandrium with concavity on medioapical region; hypandrium fused partially with epandrium (Fig. 8); subepandrial sclerite with two rounded preapical projection (Fig. 7); aedeagus with three short prongs (Fig. 11); apex of gonocoxite triangular (Fig. 10); apex of gonostylus truncate (Fig. 10); apex and dorsal preapical region of gonostylus slightly sclerotized (Fig. 10). Female terminalia. Tergite VIII more or less long, shorter than twice the length of tergite VII (Fig. 14); sternite VIII keel-like throughout; genital fork with thin and elongated arms, three oval capsules of spermathecae (Fig. 16).

Type material examined. Paratypes. Aristofolia lapila (O'), 1976, paratipo, det: J.M. Ayala L./10-Marzo-1976- Edo. Guá[rico]. S.[an] F. [rancisco] [de] Tiznados-Qda. Coronado [09 $31^{\prime} 05^{\prime \prime N} 67^{\circ} 37^{\prime} 29^{\prime \prime} \mathrm{W}$ ], [Venezuela], col: Luis A. Plaza Ayala (30' JMAC, 10 INPA); Aristofolia lapila (Q), 1976, paratipo, det: J.M. Ayala L./20-Feb-1976- Edo. Gua[rico]. S.[an] F.[rancisco] [de] Tiznados-Qda. Coronado, [Venezuela], col: Luis A. Plaza Ayala (8ㅇ JMAC, 1ㅇ INPA).

Distribution. Venezuela.

\section{ACKNOWLEDGMENTS}

To Fundação de Amparo à Pesquisa do Estado do Amazonas (FAPEAM) and Conselho Nacional de Desenvolvimento Cientifico e Tecnológico $(\mathrm{CNPq})$ for financial sup- port to the Project PRONEX, Edital 016/2006, Proc. 1437/ 2007. To PNPD/CNPq for the fellowships that have allowed us to complete this work. To Jorge Gonzalez for the revision of the manuscript in English.

\section{REFERENCES}

Artigas, J. N. \& Papavero, N. 1995. The American genera of Asilidae (Diptera): Keys for identification with an atlas of female spermathecae and other morphological details. IX.10. Subfamily Asilinae Leach Lecania group, with a catalogue of the Neotropical species. Theoria 4: $33-56$.

Ayala-Landa, J.M. 1978. Contribucion al estudio de la tribu Asilini (Diptera: Asilidae). Revista de la Facultad de Agronomía 26: 31-46.

Cumming, J.M. \& Wood, D.M. 2009. Adult morphology and terminology, p. 9-50. In: Brown, B.V., Borkent, A., Cumming, J.M., Wood, D.M., Woodley, N.E.\& Zumbado, M.A. (eds.). Manual of Central American Diptera. Volume 1. Ottawa, National Research Council Research Press, 950 p.

Geller-Grimm, F. 2004. A world catalogue of the genera of the family Asilidae (Diptera). Studia Dipterologica 10: 473-526.

Papavero, N. 2009. Catalogue of Neotropical Diptera. Asilidae. Neotropical Diptera 17: 1-178.

Vieira, R. 2012a. New distribution records of six species of Asilinae (Diptera, Asilidae) Latreille, 1802. Checklist 8: 779-781.

Vieira, R. 2012b. A new species of Leinendera Carrera, 1945 (Diptera, Asilidae, Asilinae) from Brazil. Biota Neotropica 12: 1-7.

Vieira, R., Rafael, J.A. \& Limeira-de-Oliveira, F. 2013. Revision of Cerozodus Bigot, 1857 (Diptera, Asilidae, Asilinae) with description of a new species from Brazil. Zootaxa 3646: 180-188.

Received 1 September 2013; accepted 11 December 2013

Associate Editor: Marcia S. Couri 